\title{
Computations of Disturbance Amplification Behind Isolated Roughness Elements and Comparison with Measurements
}

\author{
Meelan Choudhari ${ }^{1}$ Fei $\mathrm{Li}^{2}$ \\ NASA Langley Research Center, Hampton, VA 23681 \\ Michael Bynum ${ }^{3}$ \\ AMA Research Associates, Hampton, VA 23666 \\ Michael Kegerise ${ }^{4}$ and Rudolph $\mathrm{King}^{5}$ \\ NASA Langley Research Center, Hampton, VA 23681
}

\begin{abstract}
Computations are performed to study laminar-turbulent transition due to isolated roughness elements in boundary layers at Mach 3.5 and 5.95, with an emphasis on flow configurations for which experimental measurements from low disturbance wind tunnels are available. The Mach 3.5 case corresponds to a roughness element with right-triangle planform with hypotenuse that is inclined at 45 degrees with respect to the oncoming stream, presenting an obstacle with spanwise asymmetry. The Mach 5.95 case corresponds to a circular roughness element along the nozzle wall of the Purdue BAMQT wind tunnel facility. In both cases, the mean flow distortion due to the roughness element is characterized by long-lived streamwise streaks in the roughness wake, which can support instability modes that did not exist in the absence of the roughness element. The linear amplification characteristics of the wake flow are examined towards the eventual goal of developing linear growth correlations for the onset of transition.
\end{abstract}

\section{Nomenclature}

$A_{\rho u} \quad=$ measure of streak amplitude defined as one half of the maximum spanwise variation in streamwise mass flux across the wake

$b=$ width of roughness element, $\mathrm{mm}$

BAMQT = Boeing/AFOSR Mach-6 Quiet Tunnel

$\mathrm{D}=$ diameter of circular roughness element, $\mathrm{mm}$

$f \quad=$ disturbance frequency

$k=$ roughness height

$M \quad=$ Mach number

$\mathrm{N} \quad=\mathrm{N}$-factor, i.e., integrated logarithmic amplification factor of an instability mode

rms $\quad=$ root mean square fluctuation

$\operatorname{Re}_{u} \quad=$ unit Reynolds number

$\operatorname{Re}_{\theta} \quad=$ Reynolds number based on momentum thickness

$\operatorname{Re}_{k k} \quad=$ Reynolds number based on roughness height and flow conditions at this height within the incoming boundary layer

$T \quad=\quad$ static temperature, $\mathrm{K}$

$u=$ streamwise velocity, $\mathrm{m} / \mathrm{s}$

$w \quad=$ frontal half width of roughness element, $\mathrm{mm}$

$(x, y, z) \quad=$ streamwise, wall-normal, and spanwise coordinates, respectively

\footnotetext{
${ }^{1}$ Aerospace Technologist, Computational AeroSciences Branch, M.S. 128. Associate Fellow, AIAA.

${ }^{2}$ Aerospace Technologist, Computational AeroSciences Branch, M.S. 128.

${ }^{3}$ Research Engineer, Hypersonic Airbreathing and Propulsion Branch, M.S. 168.

${ }^{4}$ Research Scientist, Flow Physics and Control Branch, M.S. 170, Senior Member, AIAA.

${ }^{5}$ Research Scientist, Flow Physics and Control Branch, M.S. 170, Member AIAA.
} 


$\begin{array}{ll}\mathrm{X} & =\text { streamwise coordinate (used interchangeably with } x) \\ \delta & =\text { Boundary layer thickness based on } u / u_{\infty}=0.995 \\ \rho & =\text { density, } \mathrm{kg} / \mathrm{m}^{3} \\ \xi & =\text { normalized axial coordinate along the wake of the roughness element, }\left(x-x_{r}\right) / \mathrm{D} \\ & \\ a d & =\text { adiabatic } \\ e & =\text { edge of unperturbed boundary layer } \\ k & =\text { trip height location } \\ r & =\text { location of roughness element } \\ t r & =\text { transition onset } \\ \text { wall } & =\text { value at plate surface } \\ \infty & =\text { free stream } \\ & =\text { Sunsteady perturbation }\end{array}$

\section{Introduction}

$\mathrm{S}$ URFACE roughness is known to have a substantial impact on the aerothermodynamic loading in high Mach number flight, regardless of the state of the boundary layer along the vehicle surface. When the incoming boundary-layer flow is laminar, the presence of 3D surface roughness tends to accelerate the laminar-turbulent transition process, which can result in a dramatic increase in both drag and aerodynamic heating of the vehicle. In scramjet applications, artificial roughness elements are often employed to intentionally trip the boundary layer on the forebody of the vehicle to prevent engine unstart and to minimize the flow non-uniformities at the entrance to the combustor inlet.

Empirical observations ${ }^{1,2}$ suggest that when the roughness height exceeds a critical value, the transition front begins to move upstream relative to that over a smooth surface in the same disturbance environment (Fig. 1). The rate of upstream movement slows down at sufficiently large heights and, for roughness heights larger than the so called effective trip height, the onset of transition appears to asymptote to a location ranging from somewhere just behind the roughness element to a finite distance downstream. Both the critical and effective values of the roughness height parameter are influenced by the shape of the roughness element and by the external disturbance environment. $^{2}$

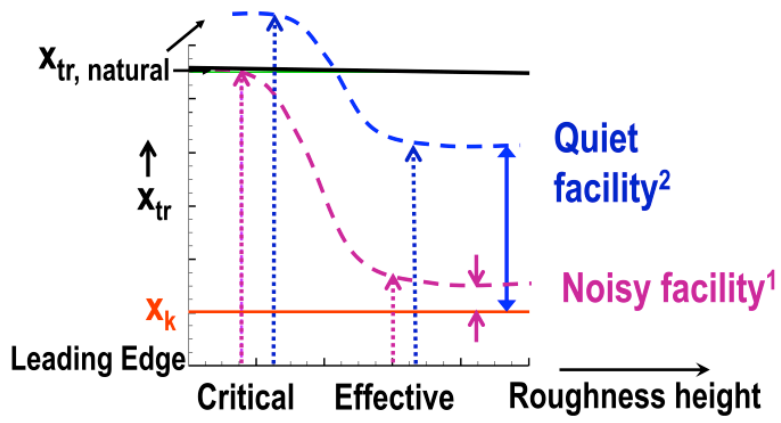

Figure 1. Schematic of variation in transition location with roughness height parameter.

Despite the common occurrence of surface roughness and its well-known impact on the vehicle design and operation for high-speed flight, the physical mechanisms underlying the transition process behind discrete roughness elements are not fully understood at this time. In principle, the roughness elements may lead to an earlier onset of transition via various physical mechanisms: ${ }^{3,4}$ (1) accelerated growth of existing instability modes; (2) new classes of instabilities in the trip modified flow, which may be convective modes within the intermediate to far wake behind the roughness element or absolute/global instabilities of the separated flow near the element, (vortex shedding, etc.) that may or may not be coupled to one another; (3) strong transient growth of boundary layer perturbations; and (4) enhanced receptivity to the existing disturbance environment. In practice, these mechanisms may operate on their own or, more likely, in concert with one another.

American Institute of Aeronautics and Astronautics 
To help address some of the above mentioned mechanisms, the flow behind an array of ramp and diamond trips on a 1:3 scale model of the forebody of the Hyper-X vehicle was investigated in Ref. 3 . The flow in the wake of the trip array mounted on the first compression ramp of the forebody was shown to consist of prominent streamwise streaks, the signature of which had been observed in oil flow visualizations in the experiment. These streaks support multiple modes of convective instabilities and the growth of the instabilities was strong enough to cause transition onset before the end of the first ramp as measured during an earlier set of wind tunnel experiments. The concave streamline curvature associated with the ramp was noted to play a crucial role in amplification of the streaks near the compression corners and, hence, in sustaining the streak amplitudes over the length of the forebody if the flow were to remain laminar for that long. The predicted role of convective instabilities in the wake is qualitatively consistent with the experimental observation ${ }^{2}$ that the disturbance environment has a significant effect on measured transition.

Follow-on analysis ${ }^{4}$ confirmed that, due to the absence of concave streamline curvature over a flat plate boundary layer, the wake perturbation behind a roughness element in a Mach 3.5 boundary layer becomes weaker with increasing distance behind the roughness; yet the rate of decay is small enough to allow a significantly long region of wake instability that supports logarithmic amplification factors ( $\mathrm{N}$-factors) that are typically correlated with transition onset in a broad class of boundary layer flows. Variation of estimated transition onset location with respect to trip height was qualitatively consistent with the classical measurements. ${ }^{1}$ Numerical simulations ${ }^{4}$ also demonstrated that any general form of unsteadiness from the upstream flow can interact with the roughness element to excite the wake instability modes; hence, no additional ingredients are required for the receptivity process associated with these modes.

Kegerise et al. ${ }^{5}$ acquired detailed experimental measurements of both the mean flow and unsteady disturbance evolution behind a roughness element in the Mach 3.5 Supersonic Low Disturbance Tunnel at NASA Langley Research Center. A variety of roughness shapes were investigated, including a diamond roughness element, a circular roughness element, an asymmetric, right-triangle roughness element, and an inclined fence roughness element that was oriented 45 degrees relative to the free stream. The depth and quality of these measurements provided a detailed picture of the transition process behind the roughness element and also enabled a comprehensive comparison with the wake instability theory from Refs. 3 and 4. In particular, the computational predictions and experimental measurements showed good agreement with respect to the mean wake structure, disturbance mode shapes, frequencies, and amplification characteristics for a symmetric, diamond-shaped roughness element. Furthermore, the measurements by Kegerise et al. ${ }^{5}$ also showed that the instability amplification behind roughness elements with asymmetric planforms was weaker than that behind symmetric planform shapes (namely, diamond and circle) with the same height and frontal width. Hence, the onset of transition was also delayed in the asymmetric cases. On the other hand, the stability and transition characteristics for the two symmetric elements were found to be very close to each other, suggesting that the exact shape of the symmetric planform may be somewhat secondary in the transition process.

The flow behind an isolated roughness element was also investigated by Chang et al., ${ }^{6}$ who addressed the potential onset of spontaneous unsteadiness behind a roughness element with a height that is close to the boundary layer thickness. They found that the wake flow spontaneously became unsteady at sufficiently large roughness heights, and exhibited a complex interplay between the unsteadiness in the separation region immediately upstream of the roughness element and the disturbance motion farther downstream within the wake. The latter interplay indicated the possibility of coupling between the local instabilities of the wake flow and absolute instabilities near the roughness element. Strong tonal perturbations amplifying within the near-wake region were also detected via measurements of surface pressure fluctuations in a quiet flow experiment ${ }^{7}$ at $M \approx 6$ and recent numerical simulations of that experiment. ${ }^{8}$ Subsonic boundary layers with roughness elements are also known to support absolute instabilities, ${ }^{9-11}$ but those appear to be associated with the separation region immediately behind the roughness element rather than ahead of it. Roughness induced transition is currently an active area of research and the reader is referred to Refs. 12-39 for additional recent findings in this area. This body of work includes stability of roughness wakes, ${ }^{15,19,32}$ numerical simulations, ${ }^{11,18,20,24,27,29,33-36,38,39}$ wind tunnel experiments, ${ }^{12,21,23,25,26,28,30,31,37}$ ballistic range experiments, ${ }^{22}$ and flight measurements. ${ }^{13,17} \mathrm{~A}$ review of work predating the abovementioned references was presented by Schneider. ${ }^{14}$

The main goal of the present paper is to report progress on extending the previous comparison ${ }^{5}$ between computational predictions and experimental observations of roughness wake instabilities in two separate directions: (i) hypersonic Mach numbers, and (ii) roughness element with an asymmetric planform. To that end, computations are performed for a circular roughness element in the Mach 6 Boeing/AFOSR Mach-6 Quiet Tunnel (BAMQT) wind tunnel facility at Purdue University. Because of the intrinsic difficulties with hot wire measurements at high Mach numbers, the experimental measurements in the Mach 6 case are necessarily more limited than the Mach 3.5 database by Kegerise et al. ${ }^{5}$ Yet, the available measurements by Wheaton ${ }^{30}$ and Wheaton and Schneider ${ }^{37}$ are shown

American Institute of Aeronautics and Astronautics 
to yield useful insights via comparisons with the computational predictions. The second configuration of interest involves a roughness element with planform corresponding to a right-angled triangle in a Mach 3.5 flat plate boundary layer, which enables comparisons with the detailed measurements of Kegerise et al. ${ }^{5}$

An outline of this paper is as follows. The roughness configurations of interest and the associated flow conditions are outlined in Section II. The mean wake structure behind the circular roughness element at Mach 6 and the instability characteristics of wake flow are described in Section III. Results pertaining to the right triangle roughness element in a supersonic boundary layer are presented in Section IV. A summary and concluding remarks are presented in Section V.

\section{Flow Configurations}

The two main flow configurations of interest in this paper are described in sections IIA and IIB, respectively.

\section{A. $\quad M=5.95$ Nozzle Roughness}

The first roughness configuration models the experiment by Wheaton and Schneider ${ }^{37}$ for roughness heights that are post critical but well below the effective roughness height. The roughness element consists of a $5.97 \mathrm{~mm}$ diameter micrometer head that is mounted vertically at a distance of $x=1.924$ meters from the nozzle throat in the BAMQT at Purdue University (Fig. 2(a)). A range of roughness heights was considered during the experiment and a selected subset of those cases has been investigated computationally as noted in Table 1. The case notation in Table 1 includes the freestream Mach number followed by the height of the roughness element in micrometers, e.g., the case M6k3300 corresponds to the circular roughness element of height 3300 micrometers (i.e., $3.3 \mathrm{~mm}$ ) in the Mach 6 tunnel. The nominal flow conditions are held fixed for all cases corresponding to a specific Mach number (i.e., a specific wind tunnel facility). The nozzle temperature is based on finite element analysis by Skoch (Wheaton, private communication, 2012); it varies with the axial coordinate and asymptotes to $298 \mathrm{~K}$ at the downstream end of the nozzle.

According to the measurements by Wheaton and Schneider, ${ }^{37}$ the nozzle wall boundary layer remains completely laminar at $k=2.54 \mathrm{~mm}$ and, hence, that case corresponds to a subcritical roughness height. Measurements indicated that $k=2.79 \mathrm{~mm}\left(R e_{k k}=355\right)$ may be regarded as a near-critical height since, for this height, incipient transition is observed near the downstream end of the apparatus. Accordingly, the two cases $k=2.79 \mathrm{~mm}$ (M6k2790) and $k=$ $3.30 \mathrm{~mm}$ (M6k3300) have been chosen for computational analysis. The computed boundary layer thickness at the roughness location corresponds to $\delta=8.38 \mathrm{~mm}$, which agrees well with the value obtained by interpolating the data in Table 2 from Ref. 38.

\section{B. $\quad M=3.5$ Right Triangle Roughness}

Figure 2(b) displays a schematic of the triangular roughness employed by Kegerise et al. ${ }^{5}$ The planform shape corresponds to a right-angled triangle with two equal sides, one of which is aligned with the free stream. The roughness element is placed approximately $41.3 \mathrm{~mm}$ downstream from the sharp leading edge of a $406.4 \mathrm{~mm}$ long flat plate model with a tapered planform. The frontal width of the triangular roughness is given by $b=2 w=3.6$ $\mathrm{mm}$, while the trip height, $k$, is equal to $0.3445 \mathrm{~mm}$. The stagnation pressure is equal to $206.8 \mathrm{kPa}$ ( $30 \mathrm{psia}$ ), so that the thickness of the unperturbed boundary layer at the roughness location is approximately $\delta=0.72 \mathrm{~mm}$, with a Reynolds number of $U_{\infty} \delta / v_{\infty} \approx 7800$. The Reynolds number, $R e_{k k}$, based on the baseline trip height $k$ and the flow conditions at this height corresponds to $R e_{k k} \approx 462$. With $R e_{a} / M_{e}$ at the roughness location being equal to 118.6, the correlation parameter $\left(R e_{o} / M_{e}\right)(k / \delta)$ from Ref. 13 equals approximately 57 for $k=0.3445 \mathrm{~mm}$. Based on linear stability predictions, smooth surface transition due to first mode instability is not expected to occur until $x=$ $1.0 \mathrm{~m}$, i.e., well beyond the length of the test plate. Here, we assume the flat plate to be aligned with the $y=0$ plane and the incoming freestream flow to be along the $x$ axis, so that coordinate axes $y$ and $z$ are along the wall-normal and spanwise directions, respectively.

The wind tunnel condition for case M3.5k3445 corresponds to a unit Reynolds number of $R e_{k}=10.8 \times 10^{6} / \mathrm{m}$, the free-stream temperature $T_{\infty}=92.55 \mathrm{~K}$, and the surface temperature normalized with respect to adiabatic surface temperature corresponds to $T_{\text {wall }} / T_{a d}=1.03$. The non-dimensional roughness height scaled by boundary layer thickness $\delta$ corresponds to $k / \delta \approx 0.48$, and $b / k$ (roughness width to height ratio) $\approx 10.4$. At the roughness height of $k / \delta \approx 0.48$, the local Mach number is moderately supersonic $\left(M_{k} \approx 1.5\right)$. The right-triangle roughness element has a planform size that is larger than the local thickness of the unperturbed boundary layer $(2 w / \delta \approx 5)$. In contrast, the diameter, $D$, of the circular roughness element employed in the BAMQT experiments at Purdue University ${ }^{37}$ is smaller than the estimated boundary layer thickness $(D / \delta \approx 0.7)$.

American Institute of Aeronautics and Astronautics 


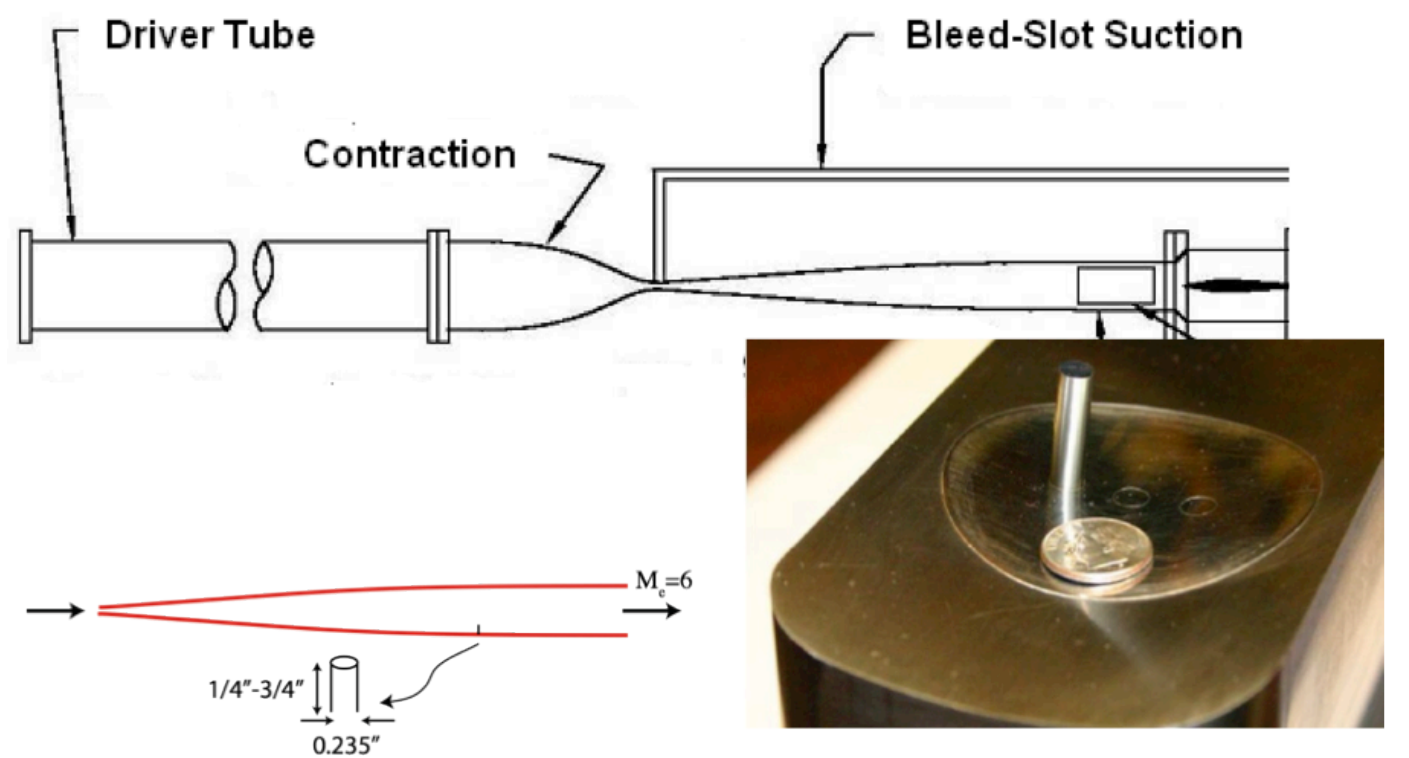

(a) Circular roughness element in Mach 6 nozzle. Schematic based on Wheaton and Schneider. ${ }^{37}$

Top view

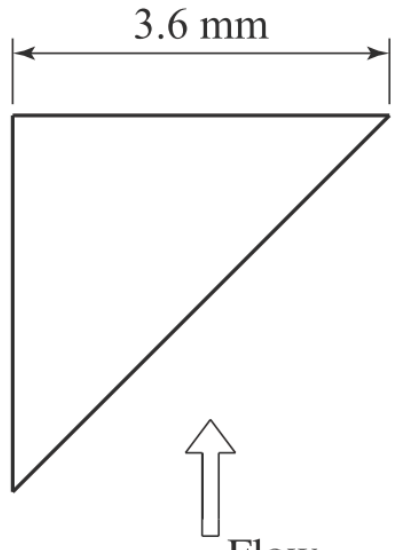

Front view

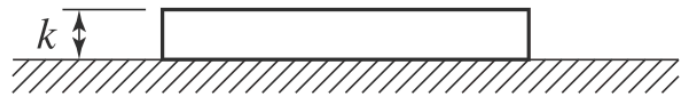

(b) Right triangle roughness element with $k=344.5 \mu \mathrm{m}$ in a Mach 3.5 flat plate boundary layer. Schematic corresponds to Fig. 3(c) from Kegerise et al.

Figure 2. Roughness configurations of interest

Table 1 Summary of Flow Configurations

\begin{tabular}{cccccccccc}
\hline \hline case & $M_{e}$ & $R_{u}\left(m^{-1}\right)$ & $T_{0}(\mathrm{~K})$ & $\begin{array}{c}P_{0} \\
(\mathrm{kPa})\end{array}$ & $x_{r}(\mathrm{~m})$ & $T_{\text {wall }} T_{a d}$ & $\begin{array}{c}\text { Planform } \\
\text { Size }\end{array}$ & $k(\mathrm{~mm})$ & $R e_{k k}$ \\
\hline M6k2790 & 5.95 & $6.88 \times 10^{6}$ & 433 & 608.1 & 1.924 & $\approx 0.8$ & $D=5.97 \mathrm{~mm}$ & $\begin{array}{c}2.79 \\
3.30\end{array}$ & $\begin{array}{c}355 \\
\text { M6k3300 }\end{array}$ \\
& & & & & & & & \\
M3.5k3445 & 3.5 & $10.8 \times 10^{6}$ & 319.3 & 206.8 & 0.0413 & $\approx 1.03$ & $w=1.8 \mathrm{~mm}$ & 0.3445 & 547 \\
\hline \hline
\end{tabular}




\section{Circular roughness element along Mach 6 Nozzle Wall}

This section first outlines the structure of the mean wake flow behind the circular roughness element in the Mach 6 nozzle and subsequently describes the characteristics of the instability modes supported by this base flow. The mean flow in the presence of the roughness element is computed by solving the compressible Navier-Stokes equations with the same algorithm and flow solver as that described by Kegerise et al. ${ }^{5}$ for a diamond shaped roughness element in a Mach 3.5 boundary layer. ${ }^{5}$ The grid topology and the underlying resolution is also very similar. Since a grid convergence study had already been performed during the earlier work for a Mach 3.5 configuration, ${ }^{4,5}$ further assessment was considered unnecessary during this follow-on effort. The possibility of selfsustained unsteadiness in the immediate vicinity of the roughness element cannot be ruled out entirely. ${ }^{4}$ However, the main focus herein is to compare the stability characteristics in the mean wake flow and, because the L2 norms of the residual levels had dropped to $\mathrm{O}\left(10^{-11}\right)$ or less when they leveled off, the wake flow computed via local time stepping was assumed to provide a meaningful basic state for the analysis of wake instabilities. The stability of this flow is investigated using a 2D (i.e., planar) eigenvalue analysis as described by Choudhari et al. ${ }^{4}$

\section{A. Mean Wake Flow Behind the Roughness Element}

To help understand the mean wake structure, crossplane contours of streamwise mass flux across the wake in the M6k3300 case are shown in Fig. 3. The underlying curved domain is unrolled to a flat surface, so that the abscissa, $z$, corresponds to distance along the circumference of the nozzle wall and the ordinate, $y$, represents the radial distance from the wall. The qualitative features of the wake contours in Fig. 3 are analogous to those in Fig. 4 of Ref. 32 for a diamond roughness element of larger planform size. Both cases display a progressive roll-up of slower moving fluid in the vicinity of the centerline as the wake flow evolves from the near-wake region to farther downstream locations. The low-speed streak along the centerline is flanked by a pair of high-speed streaks associated with the horse-shoe vortex system that is created when the originally spanwise vorticity in the incoming boundary layer wraps around the roughness element. Consistent with the shorter spanwise scale for the circular roughness element in the present case, the azimuthal (spanwise) gradient of the wake flow appears to be stronger than those for the wider roughness element in Ref. 32.

Wall-normal profiles of mass flux at selected stations are plotted in Fig. 4. Figure 4(a) shows the mass flux profiles associated with the unperturbed boundary layer along the spanwise boundary of the computational domain that is away from the roughness element. Figs. 4(b) and 4(c) indicate the profiles along the symmetry plane of the wake $(z=0)$ for $k=2.79 \mathrm{~mm}$ and $k=3.30 \mathrm{~mm}$, respectively. The centerline profiles clearly display the lift up effect mentioned earlier, which becomes stronger as the roughness height is increased from $k=2.79 \mathrm{~mm}$ to $k=3.30$ $\mathrm{mm}$. The large change in profiles and increased thickening of the centerline boundary layer from Fig. 4(b) to Fig. 4(c) as the roughness height is increased by just 18 percent, in comparison with the change from Fig. 4(a) to Fig. 4(b), clearly shows the nonlinear effect of roughness height on the dynamics of the wake flow.

The mean flow evolution across Figs. 3(a) through 3(e) indicates a slow spanwise spreading of the wake. Spanwise profiles of mass flux at a boundary layer height corresponding to the maximum spanwise variation are plotted in Figs. 5(a) and 5(b) for $k=2.79 \mathrm{~mm}$ and $k=3.30 \mathrm{~mm}$, respectively. Several trends may be noted from these two figures. First, the peak spanwise variation occurs at progressively larger heights as $x$ increases along the wake. Second, both the mass-flux deficit along the centerline and the excess associated with the high-speed streak on either side also increase in magnitude along the streamwise direction. Both of the above trends are particularly apparent within the interval of $x=2.08 \mathrm{~m}$ to $x=2.78 \mathrm{~m}$. However, the wake evolution appears to slow down between $x=2.78 \mathrm{~m}$ and to $x=3.0 \mathrm{~m}$ as the spanwise profiles display relatively smaller change between these two locations. Observe that the change in wall-normal profiles between these farthest downstream locations was also weaker as seen from Figs. 4(b) and 4(c). The saturation in wake evolution towards the downstream end of the domain is further confirmed by the evolution of streak amplitude at both roughness element heights (Figs. 6(a) and 6(b)). Figure 6 also suggests that the wake evolution slows down earlier at the larger roughness element height. Furthermore, the peak streak amplitude increases by nearly 80 percent when the roughness height is increased by just 18 percent, underscoring the nonlinear effect of roughness height as mentioned earlier.

American Institute of Aeronautics and Astronautics 


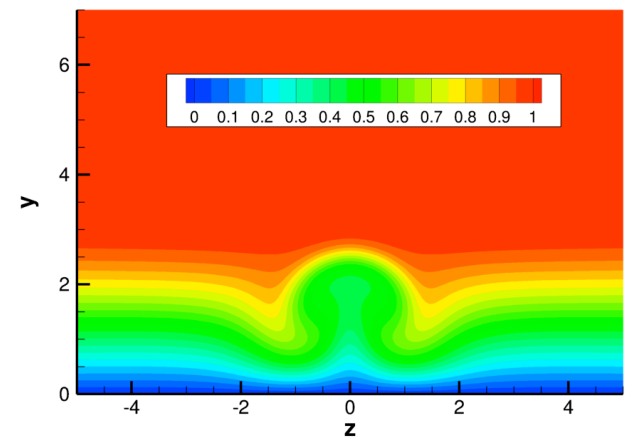

(a) $x=2.08 \mathrm{~m}(\xi=26.1)$.

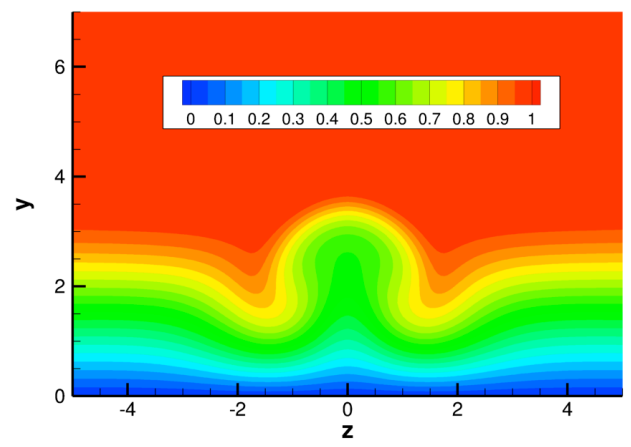

(c) $x=2.4 \mathrm{~m}(\xi=79.7)$.

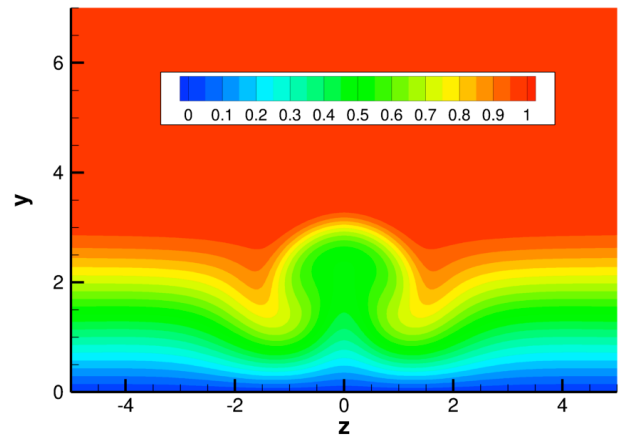

(b) $x=2.23 \mathrm{~m}(\xi=51.3)$.

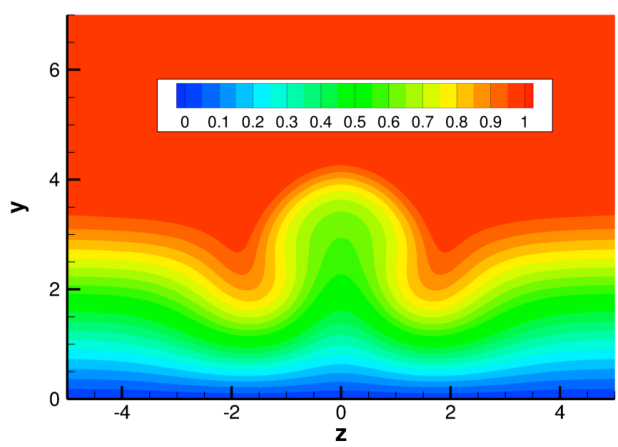

(d) $x=2.78 \mathrm{~m}(\xi=143.4)$.

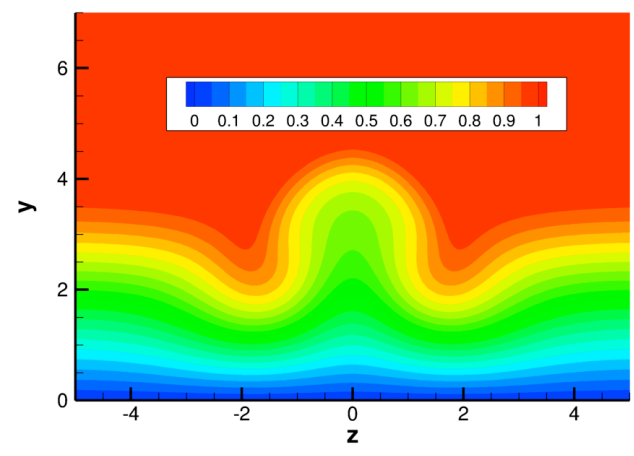

(e) $x=3.0 \mathrm{~m}(\xi=180.2)$.

Figure 3. Mean mass flux contours at selected locations in the wake of the circular roughness element for case M6k3300. Both abscissa and ordinate are normalized by the radius of the circular roughness element.

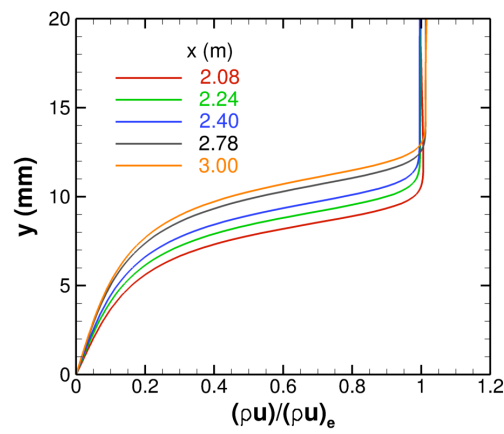

(a) Sideline.

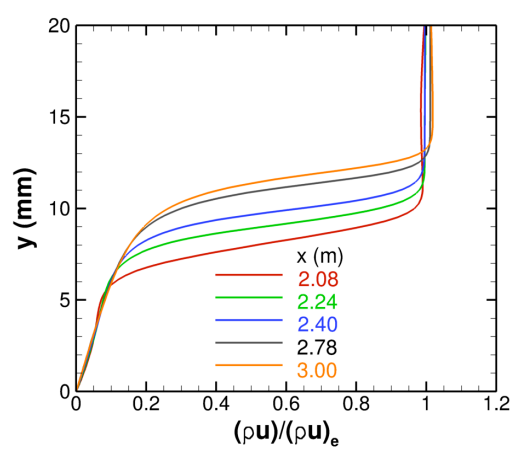

(b) Centerline $(k=2.79 \mathrm{~mm})$.

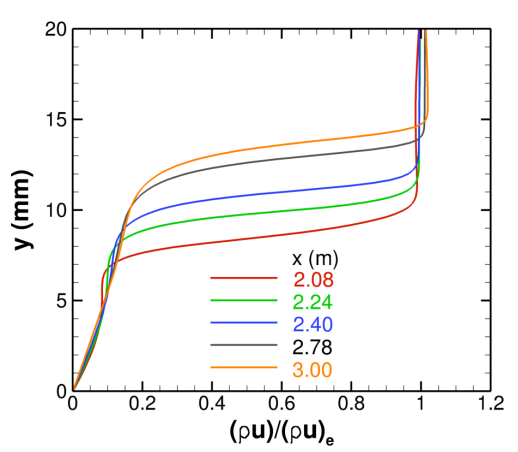

(c) Centerline $(k=3.3 \mathrm{~mm})$.

Figure 4. Sideline and centerline mass-flux profiles at selected axial locations. 


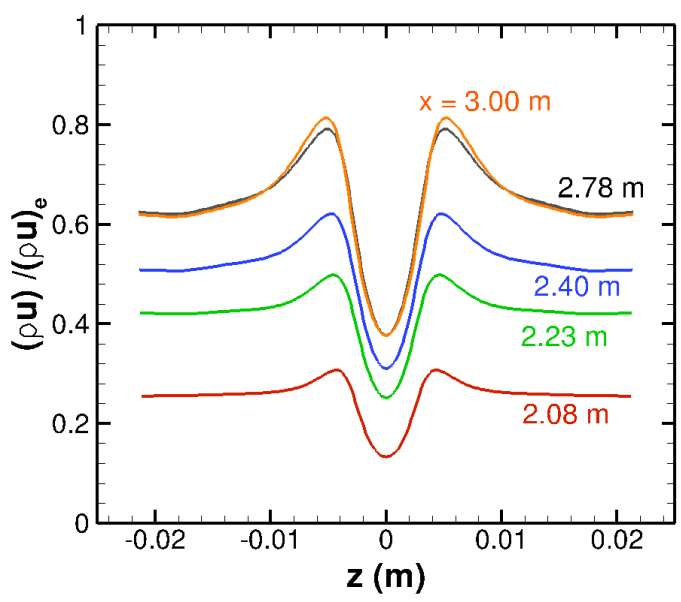

(a) $k=2.79 \mathrm{~mm}$.

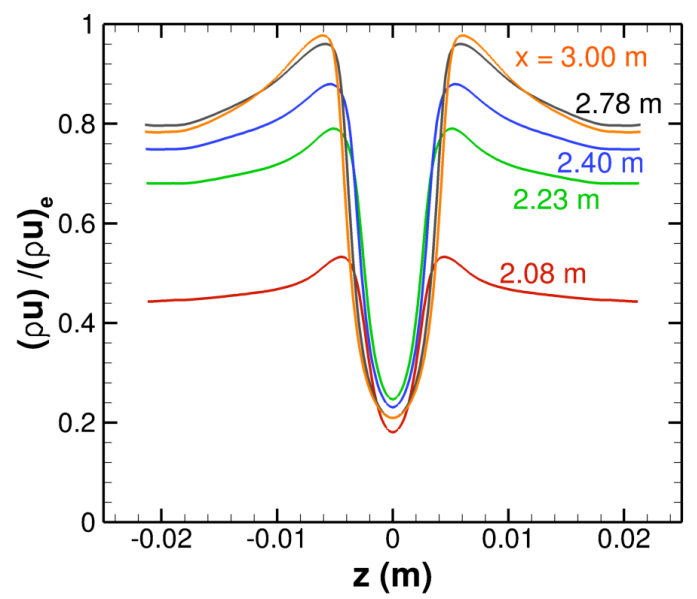

(b) $k=3.30 \mathrm{~mm}$.

Figure 5. Azimuthal mass-flux profiles at selected axial locations. The wall-normal location corresponds to maximum azimuthal variation at the location of interest.

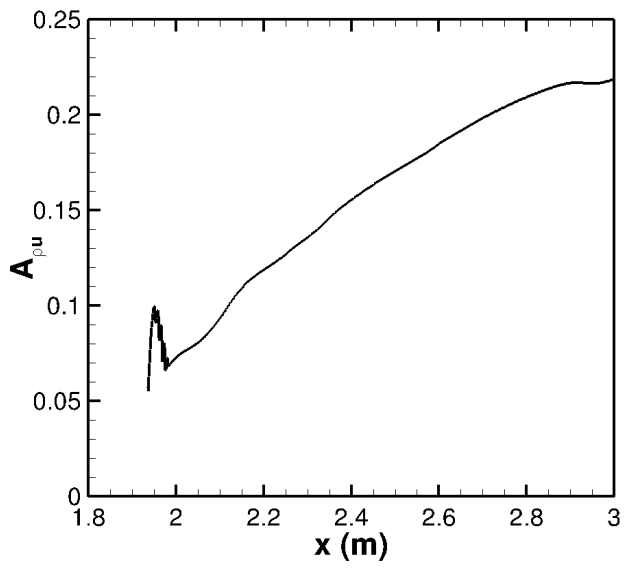

(a) $k=2.79 \mathrm{~mm}$.

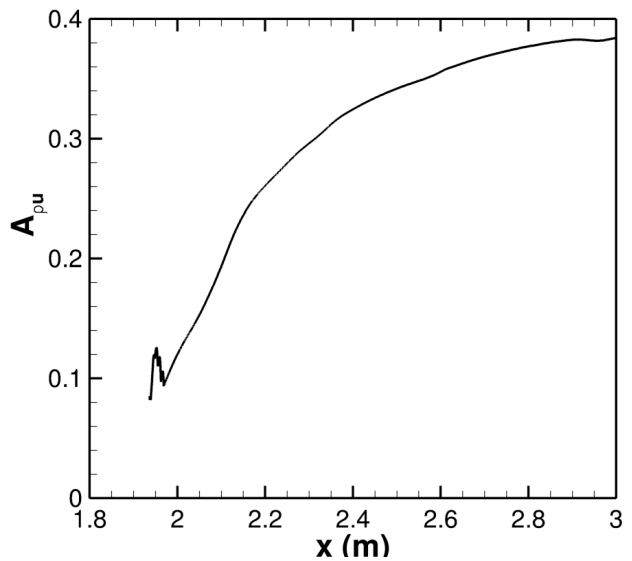

(b) $k=3.30 \mathrm{~mm}$.

Figure 6. Streak amplitude as function of axial coordinate.

\section{B. Disturbance Amplification in Wake Region}

To set the stage for the analysis of instabilities supported by the streaks within the wake region, we first consider the instability characteristics of the boundary layer flow outside the wake region. As described by Schneider ${ }^{40}$ and Li et al., ${ }^{41}$ this flow is known to support both first mode and second mode instabilities. Since the nozzle surface curvature at the roughness location and beyond is rather weak, no significant Goertler instability is expected in this region. However, the slight concave curvature may induce a proportional destabilization of both the mean flow streaks and also influence the evolution of the first and second modes. The growth rates of first and second mode instabilities at selected axial locations are shown in Fig. 7(a). Growth rate specra based on linear stability analysis of boundary layer profiles along the centerplane of the wake (as shown previously in Fig. 4(c)) are shown in Fig. 7(b) for the case M6k3300.

The growth rates of 2D second mode instabilities in the unperturbed boundary (Fig. 7(a)) are more than three times as large as the growth rates of oblique first mode waves. Because of the weak boundary layer growth along the axial direction, the frequency band of unstable second mode disturbances shifts to progressively lower values with increasing $x$. Hence, a fixed frequency second mode disturbance is unstable over a subset of axial locations 
within the region of interest. The strongly inflectional profiles along the centerline of the wake (Fig. 4(c)) are highly unstable and the peak growth rates of the predicted instabilities (Fig. 7(b)) are substantially larger than the second mode growth rates in the unperturbed boundary layer (Fig. 7(a)). Furthermore, the centerline wake profiles do not show a distinct split between first and second mode instabilities. Instead, a single peak in growth rates is observed when the disturbance frequency is varied at a fixed wake location. Furthermore, in contrast to the unperturbed boundary layer profiles, the peak growth rates of oblique and 2D modes of the instability waves along the centerline are comparable to each other as seen from Fig. 7(b). The frequency band of instability waves with large growth rates also extends over a substantially broader frequency range than that in Fig. 7(a). Furthermore, disturbances over a significant portion of this frequency range are unstable throughout the range of streamwise locations considered in Fig. 7(b). As a result, the amplification of wake instabilities is expected to be much stronger than that in the unperturbed boundary layer.

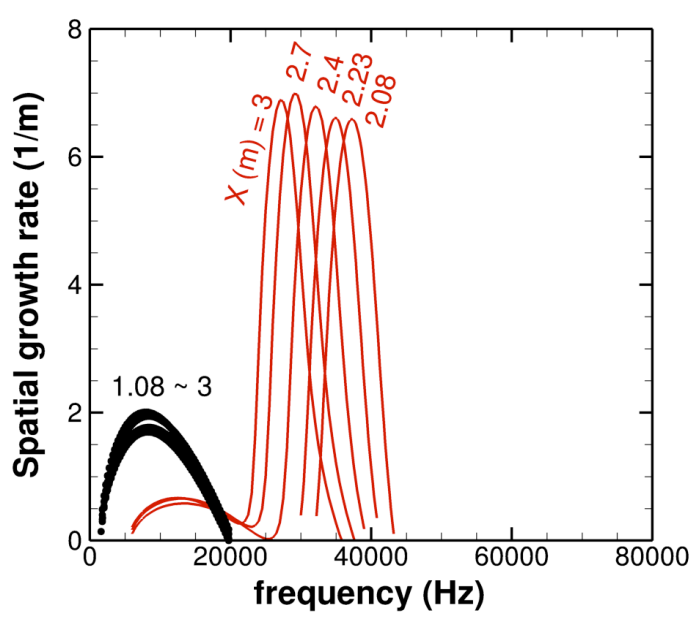

(a) Sideline profiles.

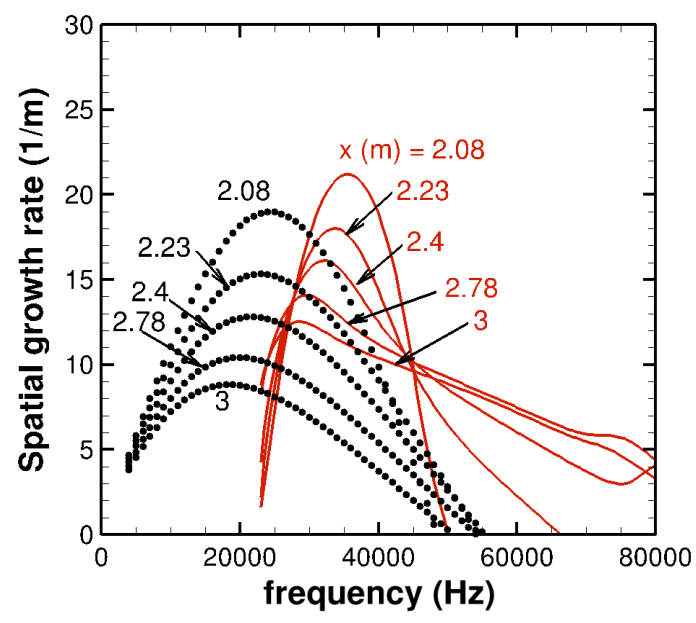

(b) Centerline profiles.

Figure 7. Frequency spectra of local growth rate at selected streamwise locations for case M6k3300 $(k=$ $3.30 \mathrm{~mm})$. The numerals attached to each curve indicate the $x$ location in meters. Red curves and black symbols denote the growth rates of $2 \mathrm{D}$ and oblique modes, respectively.

Since the spanwise and wall normal length scales of the boundary layer streaks within the wake are comparable to each other, the modified boundary layer flow has a strongly inhomogeneous character in both $y$ and $z$ directions. Therefore, its stability characteristics are more appropriately studied by solving an eigenvalue problem based on two-dimensional partial differential equations (PDEs), ${ }^{42,43,4,15,19}$ rather than using the conventional linear stability analysis, which is based on the assumption of basic state inhomogeneity in a single spatial coordinate (namely, the surface normal direction). The symmetric wake is found to support multiple families of unstable modes that may be either even (i.e., symmetric) or odd (i.e., antisymmetric) functions of the spanwise coordinate. The variation of growth rate as a function of the disturbance frequency parameter at selected streamwise locations is shown in Figs. 8(a) and 8(b) for the dominant families of even and odd modes, respectively. The associated spectra of disturbance $\mathrm{N}$-factors are shown in Figs. 9(a) and 9(b), respectively. As one moves from $x=2.08 \mathrm{~m}$ to $3.0 \mathrm{~m}$, the frequency of the locally most unstable even mode increases from approximately $25 \mathrm{kHz}$ to nearly $40 \mathrm{kHz}$. Initially, the peak growth rate increases with $x$ from $x=2.08 \mathrm{~m}$ to $x=2.23 \mathrm{~m}$ and then decreases at farther downstream locations. The overall variation in peak growth rate of the even modes is relatively weak, less than 30 percent of the global maximum in the disturbance growth rate near $x=2.23 \mathrm{~m}$. On the other hand, the peak growth rate of the odd modes decreases monotonically with $x$ and, furthermore, reduces by nearly a factor of two from $x=2.08 \mathrm{~m}$ to $x=3.0 \mathrm{~m}$. Similar to the even modes, the disturbance frequency corresponding to the peak local growth rate increases slowly from $12.5 \mathrm{kHz}$ to $17.5 \mathrm{kHz}$. Thus, the frequencies of most unstable odd modes are nearly a factor of two lower than those of the most unstable even modes. Unlike the supersonic case in Refs. 3 and 4, the frequency range of the most amplified instability modes in Fig. 8 overlaps with the frequencies of the instability waves in the unperturbed boundary layer (Fig. 7). A similar observation was made in Ref. 32 in the context of a different roughness configuration in a Mach 6 boundary layer. 
Figure 9(a) indicates that the peak $\mathrm{N}$-factor for the even modes reaches a value in excess of 9 near the end of the measurement region at $x=3.0 \mathrm{~m}$. The peak $\mathrm{N}$-factor for the odd modes is marginally smaller at approximately 8.5. Wheaton and Schneider ${ }^{37}$ obtained unsteady surface pressure measurements along the centerline of the wake, which are shown in Fig. 9(c). The centerline transducer is only sensitive to the even mode fluctuations and shows a peak near a frequency of $30 \mathrm{kHz}$ from a normalized wake distance of 46.3 (i.e., $x=2.2 \mathrm{~m}$ ) to 76.1 (i.e., $x=2.38 \mathrm{~m}$ ). This peak frequency is rather close to the peak of even mode $\mathrm{N}$-factor spectra near $f=27.5 \mathrm{kHz}$ in Fig. 5(a). Furthermore, the peak spectral density of surface pressure fluctuation increases nearly 80 times across the two locations mentioned above. This amplitude growth amounts to an average growth rate of approximately $12 \mathrm{~m}^{-1}$, which is within 15 percent of the corresponding growth rate in Fig. 8(a).

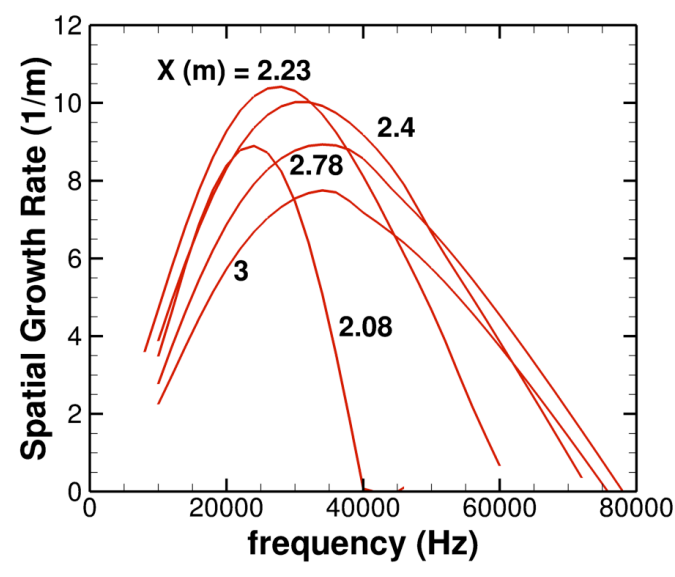

(a) Even modes.

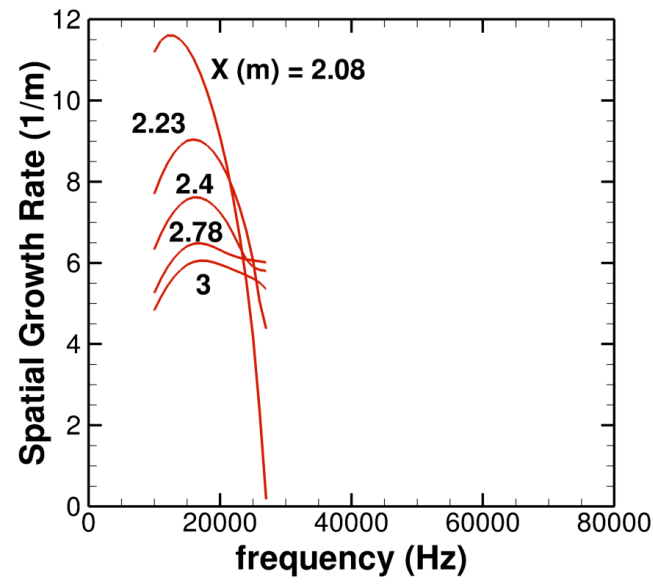

(b) Odd modes.

Figure 8. Frequency spectra of local growth rate at selected streamwise locations for case M6k3300 $(k=$ $3.30 \mathrm{~mm}$ ). The numerals attached to each curve indicate the $x$ location in meters.

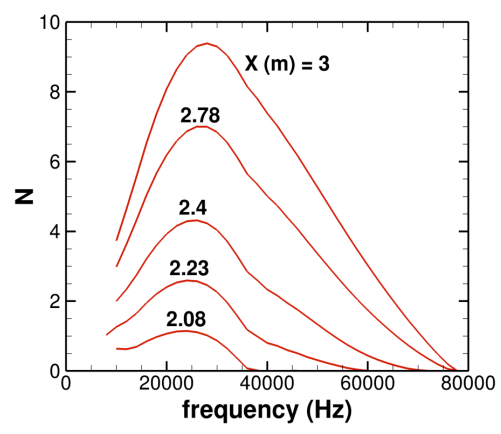

(a) Even modes.

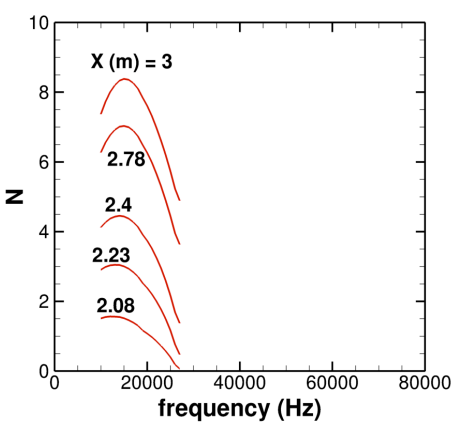

(b) Odd modes.

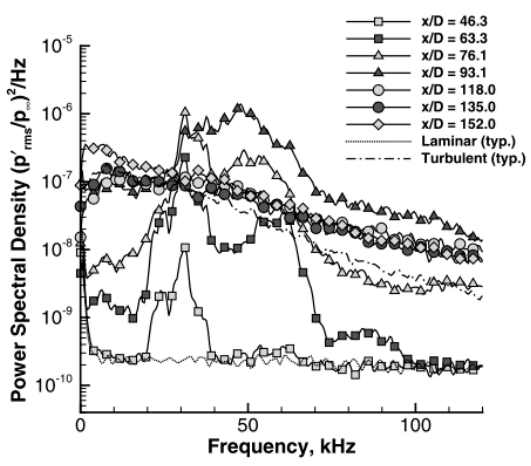

(c) Surface pressure fluctuations measured in experiment. ${ }^{37}$ The normalized distance $x / D$ is measured downstream of the roughness element as against from the nozzle throat as in this paper.

Figure 9. Frequency spectra of $\mathrm{N}$-factors at selected streamwise locations for case M6k3300 $(k=3.30 \mathrm{~mm})$. The numerals attached to each curve in parts (a) and (b) indicate the $x$ location in meters. 


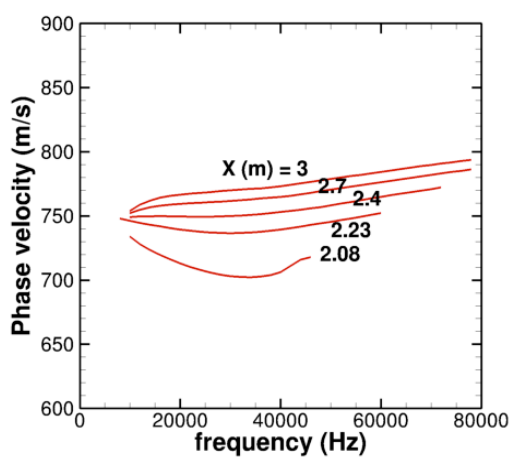

(a) Even modes.

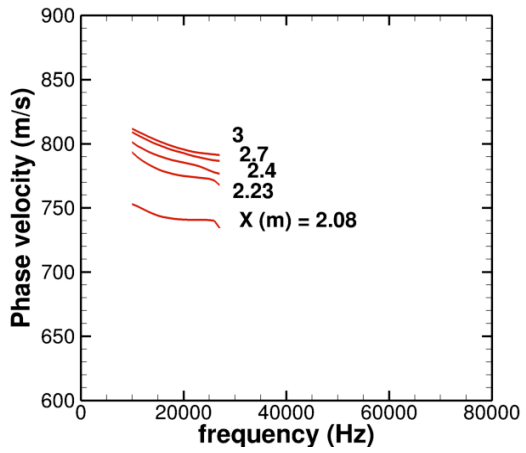

(b) Odd modes.

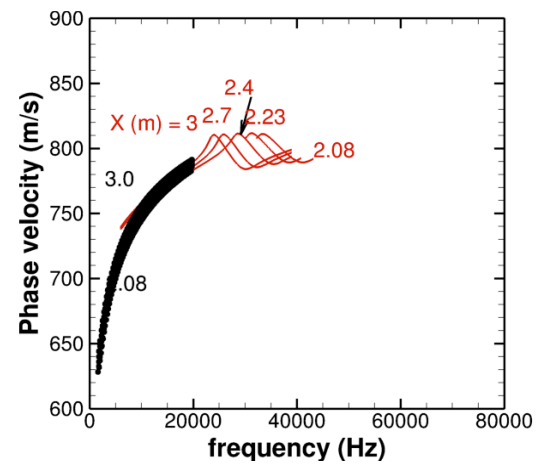

(c) Oblique first mode (black symbols) and 2D second mode (red curves) instabilities of sideline profiles.

Figure 10. Phase velocity spectra of wake instabilities at selected streamwise locations for case M6k3300 $(k=3.30 \mathrm{~mm})$.

The phase velocity of the even and odd modes as a function of frequency at the selected streamwise locations is shown in Figs. 10(a) and 10(b), respectively. In the frequency range where the two modes overlap (i.e., frequencies between approximately $10 \mathrm{kHz}$ to $25 \mathrm{kHz}$ ), the phase velocity of the odd modes is slightly higher than those of the even modes. For each mode type, the overall phase velocity increases along the downstream direction. Phase velocities of the oblique first mode and 2D second mode disturbances supported by the unperturbed boundary layer (i.e., sideline profiles) are shown for comparison in Fig. 10(c). A comparison of these predictions with those in Figs. 10 (a) and 10(b) suggests that the phase velocities of the oblique first mode waves and 2D second mode waves along the sideline are relatively closer to those of the odd modes within the wake, especially for $x \geq 2.23 \mathrm{~m}$. On the other hand, the most unstable even modes tend to have somewhat lower phase velocity over a significant range of wake stations.

Variation of growth rates and N-factors with disturbance frequency at selected wake stations for the M6k2790 case is shown in Figs. 11(a) and 11(b), respectively. Only the odd mode is included in these figures because the even mode growth rates becomes significantly smaller at this reduced roughness height. The reduction in even mode growth rates at smaller roughness heights was also noted at supersonic Mach numbers $(\mathrm{M}=3.5)$ in Ref. 4 . The peak growth rates and N-factors of the odd mode disturbances are now comparable with those of the unperturbed boundary layer. This observation is consistent with the experimental finding that $k=2.79 \mathrm{~mm}$ is barely greater than the minimum critical roughness height. However, since the even modes are found to be only weakly unstable in this case, the association between the analysis results and the measured centerline disturbance spectra by Wheaton and Schneider ${ }^{37}$ is not entirely clear at this stage. Additional computations including an analysis of uncertainty in the experimental parameters may be helpful in resolving this difference.

Representative mode shapes for the streamwise mass-flux fluctuations associated with the most unstable families of even and odd modes for $k=3.30 \mathrm{~mm}$ are shown in Figs. 12(a) and 12(b), respectively. Fluctuations associated with the dominant even mode are concentrated near the top of the mushroom-shaped flow structure associated with the upwelling of the secondary flow, i.e., in the region of increased wall-normal shear $(d u / d y)$. This mode shape is very similar to that discussed by Choudhari et al. ${ }^{4}$ in the context of a diamond roughness element in a Mach 3.5 boundary layer. In contrast, a variety of other mode types were encountered in the context of a Mach 6 boundary layer during the study in Ref. 32. The peak streamwise mass-flux fluctuations associated with the odd modes are concentrated just outside the centerline (Fig. 12(b)) and, hence correspond to mode C in the terminology of Ref. 32. Of course, by virtue of the odd parity, the streamwise fluctuations associated with these modes are identically zero at the center (i.e., the top) of the mushroom structure and the peak velocity fluctuations occur between the centerline and the region of high spanwise gradients on the side of the mushroom-shaped flow structure.

American Institute of Aeronautics and Astronautics 


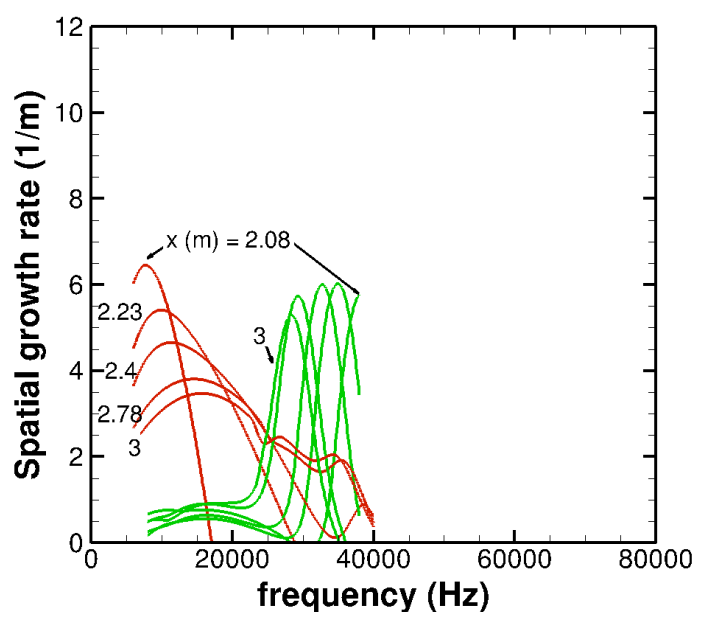

(a) Growth rate spectra.

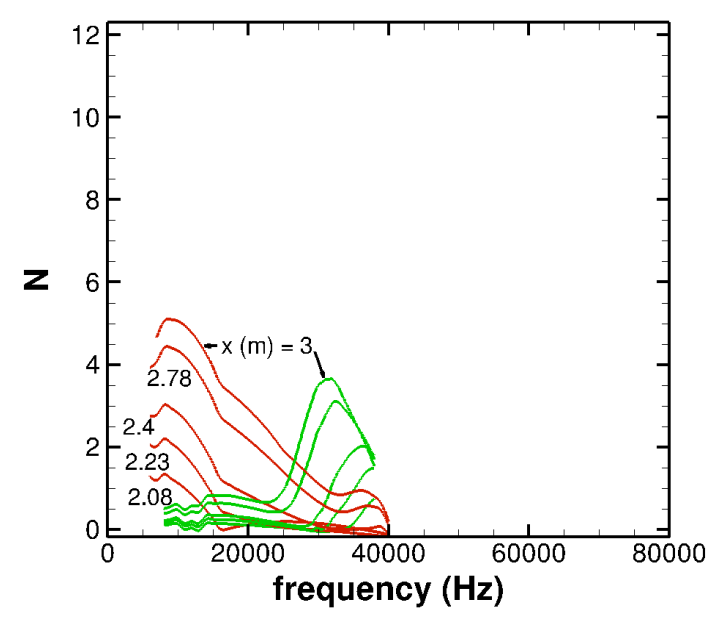

(b) N-factor spectra.

Figure 11. Frequency spectra of instability modes at selected streamwise locations for case M6k2790 $(k=$ $2.79 \mathrm{~mm})$.

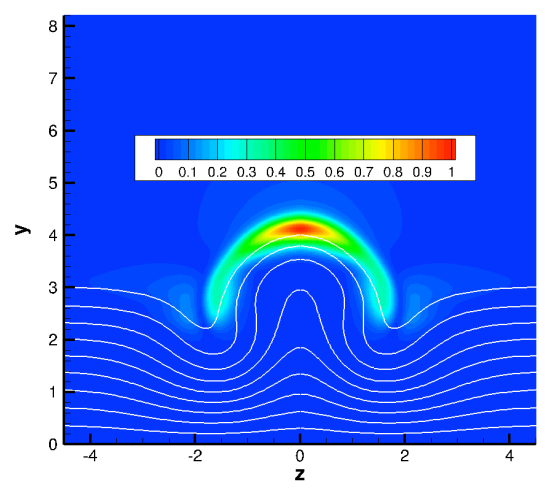

(a) Even mode for $f=30 \mathrm{kHz},\left|(\rho u)^{\prime}\right|$ mode shape.

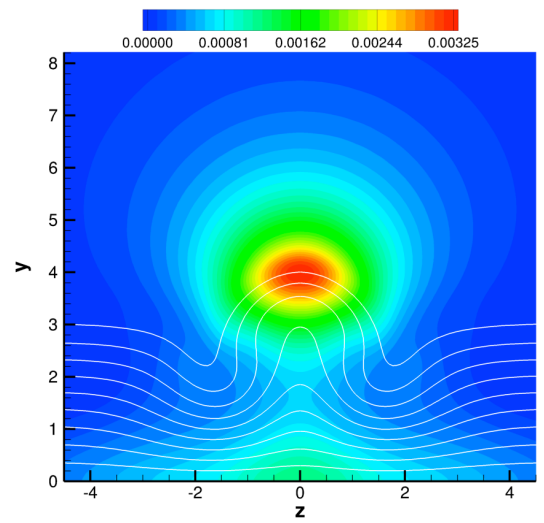

(c) Even mode for $f=30 \mathrm{kHz},\left|\mathrm{p}^{\prime}\right|$ mode shape.

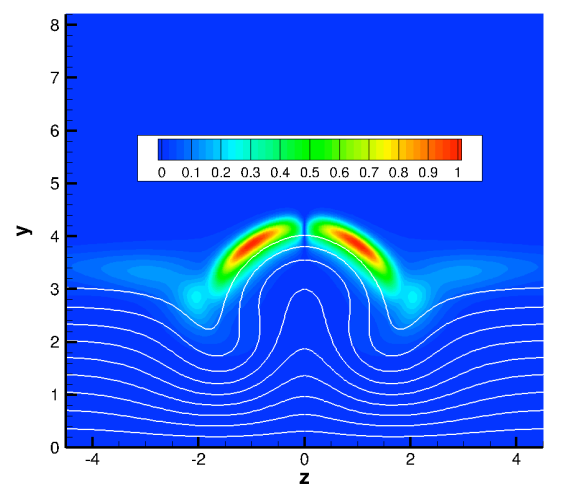

(b) Odd mode for $f=15 \mathrm{kHz},\left|(\rho u)^{\prime}\right|$ mode shape.

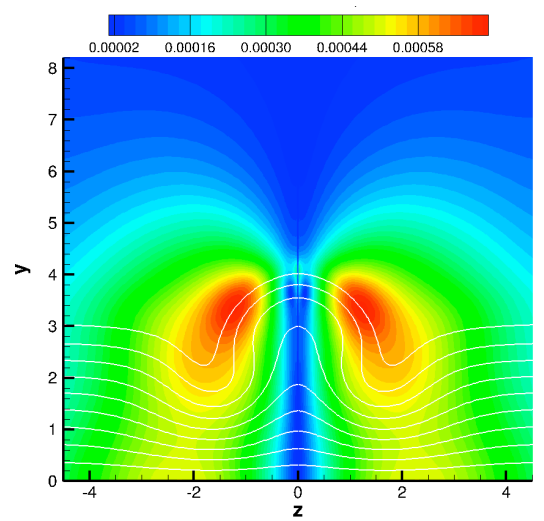

(d) Odd mode for $f=15 \mathrm{kHz},\left|\mathbf{p}^{\prime}\right|$ mode shape.

Figure 12. Mode shapes of dominant instability modes at $x=2.7 \mathrm{~m}$ (case M6k3300).

Due to the challenges in using a hot wire to make detailed, off-surface measurements in high-speed boundary layers, the measurement of surface pressure fluctuations provides a promising alternative for tracking the evolution of boundary layer instabilities. ${ }^{37}$ Representative mode shapes of pressure fluctuations associated with even and odd modes of instability at $x=2.7 \mathrm{~m}$ are plotted in Figs. 12(c) and 12(d), respectively. The peak surface pressure 
fluctuations along the surface are weaker than the off-surface maxima, but by a modest factor of approximately 2.7 in the case of the even mode and an even smaller factor of approximately 1.35 in the case of the odd mode. These findings are very similar to those described in Ref. 32 in the context of a hypothetical diamond roughness element configuration at Mach 6. Due to the antisymmetric behavior of the odd mode, a transducer at the symmetry plane that has a sufficiently small sensing area would respond only to the even mode fluctuations. In general, one must employ multiple pressure transducers across the spanwise width of the wake to obtain greater insights from the measurements of surface pressure fluctuations.

\section{Right Triangle Roughness Element in Mach 3.5 Flat Plate Boundary Layer}

Figure 13 shows a comparison between the computed and measured mean mass flux distributions across the wake at selected streamwise stations. Analogous to the circular roughness element at Mach 6 (Fig. 3), the distribution of boundary layer thickness still exhibits a centerline streak corresponding to increased boundary layer thickness. However, the mass-flux deficit associated with the centerline streak in Fig. 13 is smaller and, furthermore, the spanwise location of peak boundary layer thickness at any given streamwise location is now displaced with respect to the center plane of the roughness element and no longer has the mushroom-shaped flow structure observed earlier for the symmetric diamond roughness element. As described in Ref. 4 in the context of an inclined fence roughness element, the shape of this streak now bears a slight resemblance to the axial mass-flux contours associated with a finite amplitude crossflow vortex in a swept wing boundary layer. Furthermore, the surrounding pair of streaks corresponding to reduced boundary layer thickness involves a prominent asymmetry in terms of their strength (i.e., reduction in boundary layer thickness) and the spanwise extent of the constituent streaks. In particular, the streak on the $z<0$ side (i.e., adjacent to the flat side of the triangular planform or, equivalently, the left hand side in Fig. 13(a)) is considerably wider and deeper (i.e., corresponding to reduced boundary layer thickness) than its counterpart on the $z>0$ side. The computed wake distributions in the left half of Fig. 13 are in good qualitative agreement with the measurements of Kegerise et al., ${ }^{5}$ which are shown in the right half of Fig. 13.

The spanwise mass-flux profiles at selected streamwise locations and the associated evolution of the streak amplitude are plotted in Figs. 14(a) and 14(b), respectively. Fig. 14(a) shows that the spanwise profiles show rather small changes across the range of locations shown in the figure. Observe, again, that the high-speed streak on the $z$ $<0$ side is nearly twice as strong as that on the other side $(z>0)$ of the roughness element. Fig. 14(b) confirms that the streak amplitude rises very rapidly behind the roughness element and then undergoes a slow decay across most of the wake length included in the computational domain. The latter behavior is somewhat different from that seen earlier in Figs. 6(a) and 6(b) for the circular roughness element in Mach 5.95 boundary layer.

The asymmetric wake structure is found to sustain at least two families of unstable modes, and the typical mode shape in terms of the mass-flux fluctuations for the dominant family of modes (mode 1) is shown in Fig. 15(a). The measured unsteady mass flux distribution across the wake at the same location $(x=136.5 \mathrm{~mm})$ is shown in Fig. 15(b). The narrow-band mode shape in Fig. 15(b) is also representative of the broadband mode shape measured during the experiment. Mode 1 predicted by the $2 \mathrm{D}$ eigenvalue analysis is found to have higher growth rates than mode 2, and its mode shape also matches with the measurement as seen from a comparison between Figs. 15(a) and $15(\mathrm{~b})$.

Computed $\mathrm{N}$-factors for both instability modes predicted by the stability analysis are used to compare the predicted amplitude growth for selected disturbance frequencies with the measured amplitude evolution in Fig. 16. Since the $\mathrm{N}$-factors provide information about the growth of linear disturbances between two locations regardless of the actual disturbance amplitudes, the theoretical amplitude curves in Fig. 16 are computed by choosing the initial amplitude to be a constant that allows the envelope of the predicted amplitude evolution curves to match the measured disturbance amplitude at the first measurement station $(x=110 \mathrm{~mm})$. A reasonable agreement is observed between the predicted amplitude growth of the dominant mode (mode 1) and the measurement. However, the most amplified frequency predicted by the computational analysis $(f=59 \mathrm{kHz})$ is somewhat smaller than that measured in the experiment $(f=70 \mathrm{kHz})$ and the associated amplification factors across the range of measurement are lower than the measured growth, especially over the aft portion of the measurement range. Further work is ongoing to determine the cause behind this discrepancy.

American Institute of Aeronautics and Astronautics 


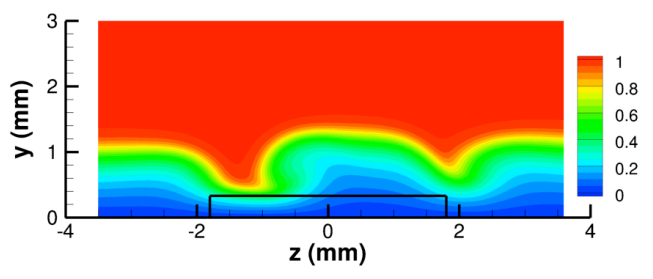

(a) $x=136.5 \mathrm{~mm}$, computed solution.

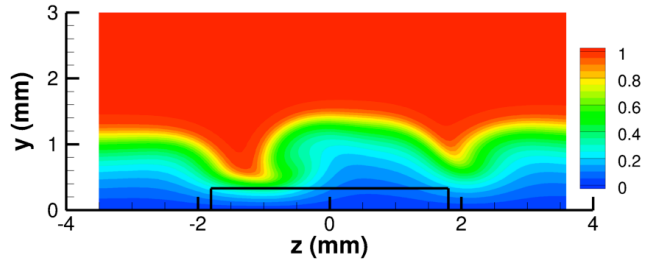

(c) $x=153.7 \mathrm{~mm}$, computed solution.

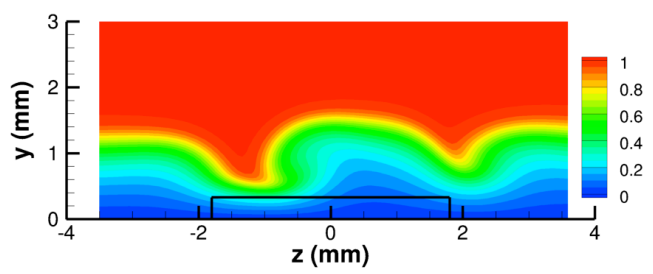

(e) $x=179.7 \mathrm{~mm}$, computed solution.

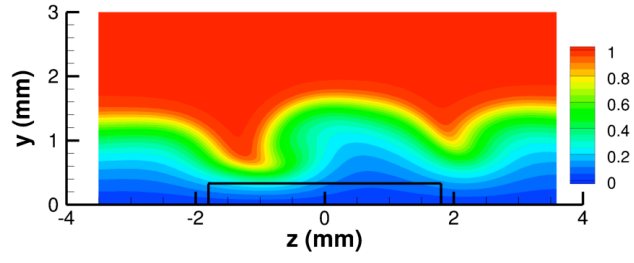

(g) $x=205.6 \mathrm{~mm}$, computed solution.

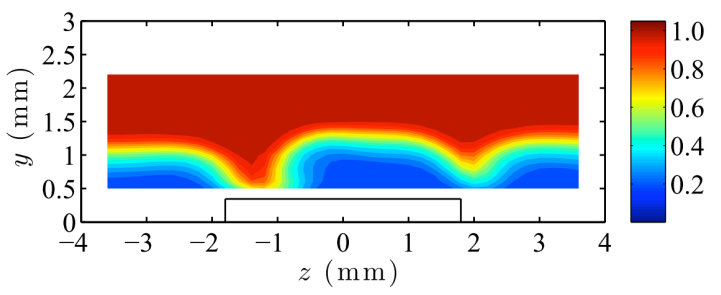

(b) $x=136.5 \mathrm{~mm}$, measurement.

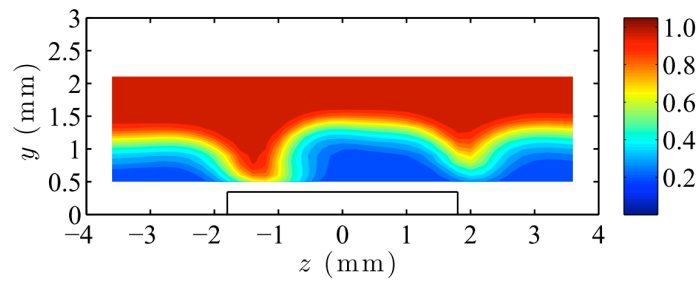

(d) $x=153.7 \mathrm{~mm}$, measurement.

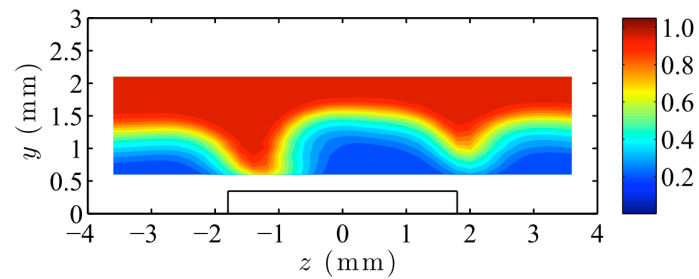

(f) $x=179.7 \mathrm{~mm}$, measurement.

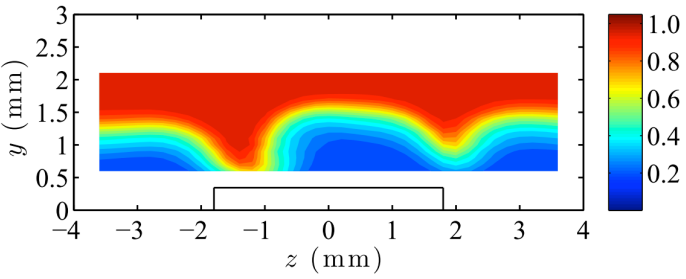

(h) $x=205.6 \mathrm{~mm}$, measurement.

Figure 13. Contours of mean mass flux $(\rho u) /(\rho u)_{\mathrm{e}}$ behind the right triangle roughness element. Mass flux values are normalized by the corresponding value at the edge of the boundary layer.

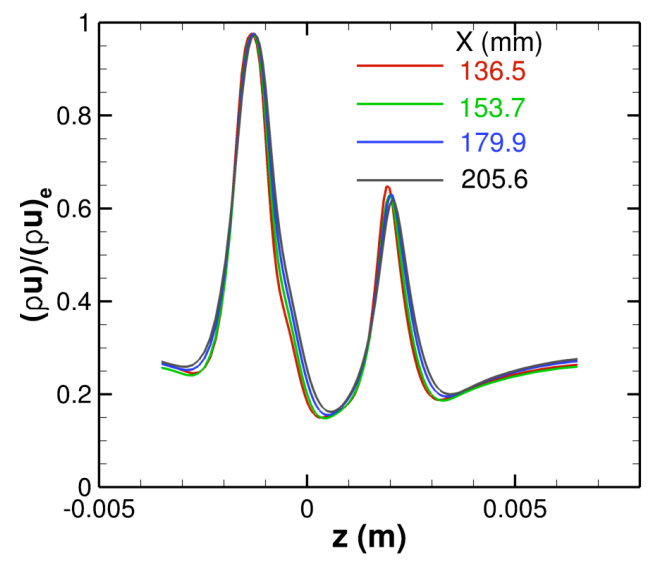

(a) Spanwise mass flux profiles at selected streamwise locations.

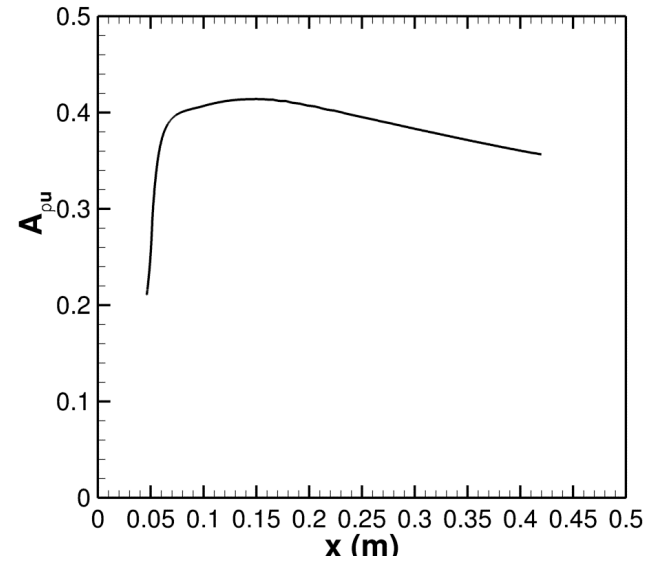

(b) Streak amplitude variation.

Figure 14. Wake profile characteristics for right-triangle roughness element. 


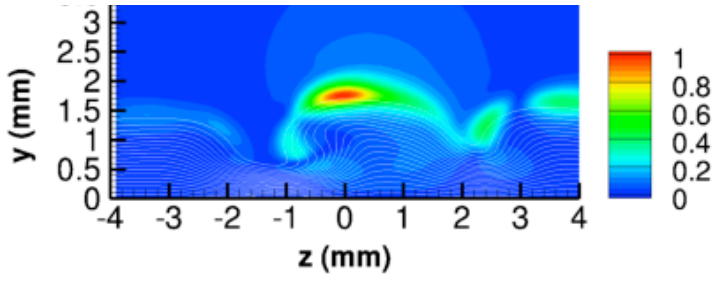

(a) $x=179.7 \mathrm{~mm}$, computed mode $1, f=52 \mathrm{kHz}$.

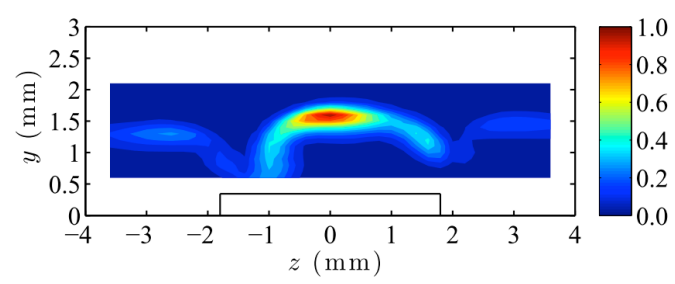

(b) $x=179.7 \mathrm{~mm}$, measurement, $f=70 \mathrm{kHz}$.

Figure 15. Comparison of computed mode shapes for mass-flux fluctuation at $f=52 \mathrm{kHz}$ with measured mass flux fluctuation $\left(\mathrm{m} / \mathrm{m}_{\mathrm{e}}\right)$ behind the right-triangle roughness element. Mode shapes are normalized such that the maximum value of the mass-flux fluctuation is equal to unity.

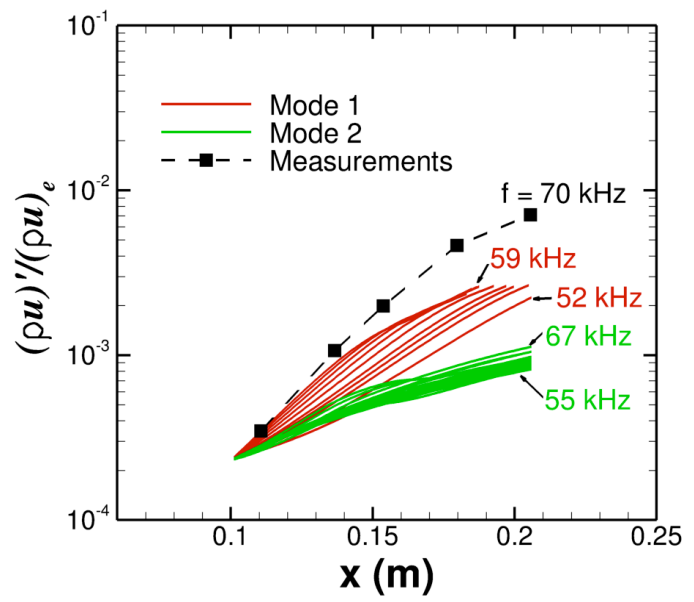

Fig. 16. Comparison of computed amplitude growth for selected disturbance frequencies for modes 1 (red curves) and 2 (green curves) with measured ${ }^{5}$ growth at $f=70 \mathrm{kHz}$ (black curve with symbols).

\section{Summary and Concluding Remarks}

This paper presented computational results for an isolated roughness element in zero pressure gradient boundary layers at Mach 5.95 and 3.5. The Mach 5.95 case involved circular roughness elements of various heights that correspond to the experiment in Purdue BAMQT by Wheaton and Schneider. ${ }^{37}$ On the other hand, the computations at Mach 3.5 extended previous comparisons with the measurements by Kegerise et al..$^{5}$ from a diamond roughness element to a right-triangle roughness element. Regardless of the Mach number, the mean flow distortion due to the roughness element is characterized by long lived streamwise streaks in the roughness element wake, which can support instability modes that did not exist in the absence of the roughness element. The right-triangle roughness element gives rise to an asymmetric wake structure that resembles a finite amplitude stationary crossflow vortex on one side.

Instability computations for the Mach 5.95 case reveal the presence of wake instability modes that are similar but not identical to those computed previously for a symmetric roughness element in a Mach 3.5 boundary layer, ${ }^{4}$ despite the underlying differences in the instability dynamics of the underlying boundary layer flows. Both even and odd modes reside on the top of the centerline streak and have comparable amplification factors, but the even modes consistently achieve slightly higher amplification ratios than the odd modes. The frequency of the most unstable even mode is in approximate agreement with the peak of the frequency spectrum measured using surfacemounted unsteady pressure transducers. The above findings also indicate that the nature of the dominant mode in any given case depends on the roughness element geometry and specific flow conditions. Previous computations ${ }^{32}$ 
for a somewhat taller and broader roughness element at different flow conditions had found that the odd (i.e., antisymmetric) wake modes had higher $\mathrm{N}$-factor values than the even modes of instability.

The computed mean wake structure behind the right-triangle roughness element in a Mach 3.5 flat plate boundary layer is in qualitative agreement with the measurements by Kegerise et al. ${ }^{33}$ in the Supersonic Low Disturbance Tunnel at NASA Langley Research Center. Computations of the wake instability reveal two different mode structures, and the mode with higher growth rates has a similar mode shape as that measured during the experiment. Despite some differences in the peak disturbance frequency and the associated amplification ratio, the stability analysis confirms that the wake flow behind the right-triangle roughness element to be significantly less unstable in comparison with that behind a diamond shaped roughness element with the same height and spanwise width.

\section{Acknowledgments}

This work was performed as part of the Revolutionary Computational Aerosciences (RCA) discipline under the Aeronautical Sciences (AS) project of NASA's Fundamental Aeronautics Program. The first author would like to acknowledge useful technical discussions with Prof. Steven Schneider and Dr. Bradley Wheaton concerning the details of their wind tunnel experiment.

\section{References}

${ }^{1}$ Van Driest, E. R. and McCauley, W. D., "The Effect of Controlled Three-Dimensional Roughness on Boundary-Layer Transition at Supersonic Speeds," J. Aero. Sc., Vol. 27, No. 4, 1960, pp. 261-271.

${ }^{2}$ Casper, K., Wheaton, B., Johnson, H., and Schneider, S., "Effect of Freestream Noise on Roughness-Induced Transition at Mach 6," AIAA Paper 2008-4291, 2008.

${ }^{3}$ Choudhari, M., Li, F., and Edwards, J. A., "Stability Analysis of Roughness Array Wake in a High-Speed Boundary Layer," AIAA Paper 2009-0170, 2009.

${ }^{4}$ Choudhari, M., Li, F., Wu, M., Chang, C.-L., and Edwards, J. A., "Laminar Turbulent Transition behind Discrete Roughness Elements in a High-Speed Boundary-Layer,” AIAA Paper 2010-1575, 2010.

${ }^{5}$ Kegerise, M. A., King, R. A., Choudhari, M., Li, F., and Norris, A., “An Experimental Study of Roughness-Induced Instabilities in a Supersonic Boundary Layer,” AIAA Paper 2014-2501, 2014.

${ }^{6}$ Chang, C., Choudhari, M., and Li, F., "Numerical Computations of Hypersonic Boundary-Layer over Surface Irregularities," AIAA Paper 2010-1572, 2010.

${ }^{7}$ Wheaton, B. and Schneider, S., "Roughness-Induced Instability in a Laminar Boundary Layer at Mach 6," AIAA Paper 2010-1574, 2010.

${ }^{8}$ Bartkowicz, M., Subbareddy, P. K., and Candler, G., "Numerical Simulations of Roughness Induced Instability in the Purdue Mach 6 Wind Tunnel," AIAA Paper 2010-4273, 2010.

${ }^{9}$ Klebanoff, P., Cleveland, W. G., and Tidstrom, K. D., "On the Evolution of a Turbulent Boundary Layer Induced by a Three-Dimensional Roughness Element,” J. Fluid Mech., Vol. 237, 1992, pp. 101-187.

${ }^{10}$ Choudhari, M. and Fischer, P., "Roughness-Induced Transient Growth,” AIAA Paper 2005-4765, 2005.

${ }^{11}$ Chang, C.-L., Choudhari, M., Venkatachari, B. S., and Li, F., "Effects of Cavities and Protuberances on Transition over Hypersonic Vehicles," AIAA Paper 2011-3245, 2011.

${ }^{12}$ Danehy, P. M., Garcia, A. P., Borg, S., Dyakonov, A. A., Berry, S. A., Wilkes-Inman, J. A., and Alderfer, D. W., "Fluorescence Visualization of Hypersonic Flow Past Triangular and Rectangular Boundary-Layer Trips," AIAA Paper 2007536, 2007.

${ }^{13}$ Berry, S. A., Chen, F.-J., Wilder, M., and Reda, D., "Boundary Layer Transition Experiments in Support of the Hypersonics Program," AIAA Paper 2007-4266, 2007.

${ }^{14}$ Schneider, S. P., "Effects of roughness on hypersonic boundary-layer transition," Journal of Spacecraft and Rockets, Vol. 45, No. 2, 2008, pp. 193-209.

${ }^{15}$ Choudhari, M., Li, F., and Edwards, J. R., “Advanced Stability Analysis Pertaining to Roughness Effects on LaminarTurbulent Transition in Hypersonic Boundary Layers," HYP/AAP Quarterly Bulletin, ed. S. Yoon, March 2008.

${ }^{16}$ Campbell, C. H., Garske, M., Kinder, J., and Berry, S. A., "Orbiter Entry Boundary Layer Flight Testing," AIAA Paper $2008-635,2008$

${ }^{17}$ Horvath, T. J., Berry, S. A., Schwarz, R., Daryabeigi, K., Splinter, S., and Ross, M., "Assessment and Mission Planning Capability for Quantitative Aerothermodynamic Flight Measurements Using Remote Imaging," AIAA Paper 2008-4022, 2008.

${ }_{18}$ Marxen, O., Iaccarino, G., and Shaqfeh, E. S. G., "Numerical Simulation of the Effect of a Roughness Element on HighSpeed Boundary-Layer Instability," AIAA Paper 2008-4400, 2008.

${ }^{19}$ Groskopf, G., Kloker, M. J., and Marxen, O., "Bi-Global Secondary Stability Theory for High-Speed Boundary-Layer Flows," in "Center of Turbulence Research, Proceedings of the Summer Program," 2008, pp. 1-18.

${ }^{20}$ Greene, P., “A Numerical Study of Purdue's Mach 6 Tunnel with a Roughness Element," AIAA Paper 2009-0174, 2009.

${ }^{21}$ Danehy, P. M., Ivey, C. B., Inman, J. A., Bathel, S. B., McCrea, A. C., Jiang, N., Webster, M., Lempert, W., Miller, J., and Meyer, T., "High-speed PLIF of hypersonic transition over discrete cylindrical roughness," AIAA Paper 2010-703, 2010. 
${ }^{22}$ Reda, D. C., Wilder, M. C., and Prabhu, D. K., "Transition Experiments on Blunt Bodies with Isolated Roughness Elements in Hypersonic Free Flight," AIAA Paper 2010-1367, 2010.

${ }^{23}$ Danehy, P. M., Ivey, C. B., Bathel, B. F., Inman, J. A., Jones, S. B., Watkins, A. N., Goodman, K. Z., McCrea, A. C., Leighty, B. D., Lipford, W. K., Jiang, N., Webster, M., Lempert, W., Miller, J., and Meyer, T., "Orbiter BLT Flight Experiment Wind Tunnel Simulations: Nearfield Flow Imaging and Surface Thermography," AIAA Paper 2010-1571, 2010.

${ }^{24}$ Redford, J. A., Sandham, N. D., and Roberts, G. T., "Compressibility Effects on Boundary-Layer Transition Induced by an Isolated Roughness Element," AIAA Journal, Vol. 48, No. 12, 2010, pp. 2818-2830.

${ }^{25}$ Tirtey, S. C., Chazot O., and Walpot, L., "Characterization of Hypersonic Roughness-Induced Boundary-Layer Transition," Exp. Fluids, Vol. 50, 2011, pp. 407-418.

${ }^{26}$ Masutti, D., Chazot, O., Donelli, R., and de Rosa, D., "Design and Ground Testing for the Expert PL4/PL5 Natural and Roughness Induced Transition," Procedures of the 7th European Symposium on Aerothermodynamics, Brugge, Belgium, May 2011.

${ }^{27}$ Yoon, S., Barnhardt, M., and Sozer, E., "Hypersonic Transition to Turbulence Triggered by Isolated Roughness Elements," AIAA Paper 2011-565, 2011.

${ }^{28}$ Passaro, A and Baccarella, D., "Roughness Induced Transition in Hypersonic Regime Over a Flat Plate," AIAA Paper 2011-2375, 2011.

${ }^{29}$ Groskopf, G., Kloker, M. J., and Stephani, K. A., “Temperature/Rarefaction Effects in Hypersonic Boundary-Layer Flow with an Oblique Roughness Element," AIAA Paper 2011-3251, 2011.

${ }^{30}$ Wheaton, B. M., "Roughness-Induced Instabilities in a Mach-6 Laminar Boundary Layer," Ph.D. Thesis, Purdue Univ., School of Aeronautics and Astronautics, West Lafayette, IN, Dec. 2012.

${ }^{31}$ Casper, K. M., Johnson, H. B., and Schneider, S. P., "Effect of Freestream Noise on Roughness-Induced Transition for a Slender Cone," Journal of Spacecraft and Rockets, Vol. 48, No. 3, 2011, pp. 406-413.

${ }^{32}$ Choudhari, M., Li, F., Chang, C., Norris, A., and Edwards, J., "Wake Instabilities behind Discrete Roughness Elements in High Speed Boundary Layers," AIAA Paper 2013-81, 2013.

${ }^{33}$ Balakumar, P. and Kegerise, M. A., "Roughness-Induced Transition in a Supersonic Boundary Layer," AIAA Paper 20133105, 2013.

${ }^{34}$ Iyer, P. S. and Mahesh, K., "High-Speed Boundary-Layer Transition Induced by a Discrete Roughness Element," J. Fluid Mech., Vol. 729, 2013, pp. 524-562.

${ }^{35}$ De Tullio, N., Paredes, P., Sandham, N., and Theofilis, V., "Laminar-Turbulent Transition Induced by a Discret Roughness Element in a Supersonic Boundary Layer," J. Fluid Mech., Vol. 735, 2013, pp. 613-646.

${ }^{36}$ Duan, Z., Xiao, Z., and Fu, S., "Direct Numerical Simulation of Hypersonic Transition Induced by Ramp Roughness Elements," AIAA Paper 2014-237, 2014.

${ }^{37}$ Wheaton, B. and Schneider, S. P., "Hypersonic Boundary-Layer Instabilities due to Near-Critical Roughness," Journal of. Spacecraft and Rockets, Vol. 51, 2014, pp. 327-342.

${ }^{38}$ Subbareddy P. K., Bartkowicz M. D., and Candler G. V., "Direct Numerical Simulation of High-Speed Transition due to an Isolated Roughness Element," J. Fluid Mech., Vol. 748, 2014, pp. 848-878.

${ }^{39}$ De Tullio, N. and Sandham, N. D., "Influence of Boundary-Layer Disturbances on the Instability of a Roughness Wake in a High-Speed Boundary Layer,” J. Fluid Mech., Vol. 763, 2015, pp. 136-165.

${ }^{40}$ Schneider, S.P. "Design of a Mach-6 Quiet-Flow Wind-Tunnel Nozzle using the e**N Method for Transition Estimation," AIAA Paper 1998-0547, 1998.

${ }^{41}$ Li, F., Choudhari, M., Chang, C.-L., Wu, M., and Greene, P., "Development and Breakdown of Goertler Vortices in High Speed Boundary Layers," AIAA Paper 2009-0705, 2009.

${ }^{42}$ Lin, R. S. and Malik, M. R., "On the Stability of Attachment-line Boundary Layers. Part I. The Incompressible Swept Hiemenz Flow," J. Fluid Mech., Vol. 311, 1996, pp. 239-255.

${ }^{43}$ Li, F. and Choudhari, M., "Spatially Developing Secondary Instabilities in Compressible Swept Airfoil Boundary Layers," Theor. Comput. Fluid Dyn., Vol. 25, 2011, pp. 65-84. 